\title{
Expression of AtWRKY33 Encoding a Pathogen- or PAMP-Responsive WRKY Transcription Factor Is Regulated by a Composite DNA Motif Containing W Box Elements
}

\author{
Bernadette Lippok, ${ }^{1}$ Rainer P. Birkenbihl, ${ }^{1}$ Gaelle Rivory, ${ }^{1}$ Janna Brümmer, ${ }^{1}$ Elmon Schmelzer, ${ }^{2}$ \\ Elke Logemann, ${ }^{1}$ and Imre E. Somssich ${ }^{1}$
}

${ }^{1}$ Abteilung: Molekulare Phytopathologie and ${ }^{2}$ Abteilung: Zentrale Mikroskopie (CeMic), Max Planck Institut für Züchtungsforschung, Carl von Linné Weg 10, 50829 Köln, Germany

Submitted 23 October 2006. Accepted 15 November 2006.

\begin{abstract}
WRKY transcription factors regulate distinct parts of the plant defense transcriptome. Expression of many WRKY genes themselves is induced by pathogens or pathogenmimicking molecules. Here, we demonstrate that Arabidopsis WRKY33 responds to various stimuli associated with plant defense as well as to different kinds of phytopathogens. Although rapid pathogen-induced AtWRKY33 expression does not require salicylic acid (SA) signaling, it is dependent on PAD4, a key regulator upstream of SA. Activation of AtWRKY33 is independent of de novo protein synthesis, suggesting that it is at least partly under negative regulatory control. We show that a set of three WRKYspecific cis-acting DNA elements (W boxes) within the AtWRKY33 promoter is required for efficient pathogen- or PAMP-triggered gene activation. This strongly indicates that WRKY transcription factors are major components of the regulatory machinery modulating immediate to early expression of this gene in response to pathogen attack.
\end{abstract}

Additional keywords: Alternaria, Hyaloperonospora parasitica, pathogen-associated molecular patterns.

WRKY proteins are a class of zinc-finger-containing transcription factors (TFs) encoded in all higher plants by large gene families. In Arabidopsis thaliana, the WRKY gene family consists of 74 members, all of which appear to be expressed. Although not solely restricted to plants, their enormous expansion during plant evolution suggests a unique role of these genes within this kingdom (Ülker and Somssich 2004). With few exceptions, genetic studies have failed to uncover specific functions associated with individual WRKY genes. Two Arabidopsis developmental mutants, ttg2 involved in trichome (Johnson et al. 2002) and mini3 involved in seed development (Luo et al. 2005), have been found to be affected in the genes AtWRKY44 and AtWRKY10, respectively. Another gene, AtWRKY52 (RRS1), was shown to confer resistance of Arabidopsis Nd-1 plants toward Ralstonia solanacearum strain GMI1000, the casual agent of bacterial wilt (Deslandes et al.

Corresponding author: Imre E. Somssich; Tel.: +49 221-5062-310; Fax: +49 221-5062-353; E-mail: somssich@ mpiz-koeln.mpg.de

* The $\boldsymbol{e}$-Xtra logo stands for "electronic extra" and indicates the HTML abstract available online contains supplemental material not included in the print edition. Two supplemental figures appear online.
2002). Interestingly, AtWRKY52 (RRS1) also was identified to be the gene affected in the $\operatorname{slhl}$ mutant showing sensitivity toward low humidity (Noutoshi et al. 2005).

Abiotic and biotic stresses are major external factors influencing the expression of WRKY genes (Eulgem et al. 2000; Ülker and Somssich 2004). The expression of more than $70 \%$ of the Arabidopsis WRKY genes is influenced by various stresses, particularly by pathogen-related stimuli (Dong et al. 2003; Hahlbrock et al. 2003).

The transcript levels of several parsley WRKY genes were affected by treatment of cells with pathogen-derived elicitors termed pathogen-associated molecular patterns (PAMPs) (Cormack et al. 2002). Virus-induced gene silencing of three tobacco WRKY genes (NtWRKY1-3) compromised $N$-genemediated resistance toward Tobacco mosaic virus (Liu et al. 2004). AtWRKY22 and AtWRKY29 were identified as important components of a PAMP-mediated defense signal transduction pathway in Arabidopsis, and transient overexpression of AtWRKY29 reduced susceptibility to the otherwise virulent pathogens Pseudomonas syringae and Botrytis cinerea (Asai et al. 2002). Likewise, overexpression of AtWRKY70 in Arabidopsis plants resulted in enhanced resistance to two tested virulent bacteria ( $\mathrm{Li}$ et al. 2004), whereas loss-of- $A t W R K Y 70$ function impaired resistance towards Erysiphe cichoracearum and enhanced susceptibility to Erwinia carotovora ( $\mathrm{Li}$ et al. 2006). Recently, functional redundancy between AtWRKY factors associated with plant defense was demonstrated by the generation of Atwrkyl8Atwrky 40 and Atwrkyl8Atwrky60 double mutants and Atwrky18Atwrky40Atwrky60 triple mutant lines (Xu et al. 2006). Whereas the corresponding single mutants showed little altered phenotypic effects upon challenge with $P$. syringae DC3000 compared with wild-type plants, the double and triple mutants clearly were more resistant toward this bacterial strain.

The involvement of MAP kinases in the rapid activation of WRKY gene expression during plant defense has been inferred from several studies. In tobacco, activation of the MAP kinases SIPK and WIPK, by means of an inducible dominant gain-offunction $N t$ MEK2 transgene, resulted in elevated expression of WRKY genes (Kim and Zhang 2004). In addition, tobacco WRKY1 was shown to be directly phosphorylated by the MAP kinase SIPK and, thereby, to mediate hypersensitive (HR)-like cell death (Menke et al. 2005). In Arabidopsis, activation of a MAP kinase pathway, triggered by the interaction of the bacterial PAMP flg22 with the membrane-associated FLS2 
receptor, resulted in enhanced gene expression of AtWRKY22 and AtWRKY29 (Asai et al. 2002). Similarly, activation of AtWRKY33 and AtWRKY53 was shown to involve a MAP kinase pathway following elicitation of Arabidopsis seedlings with chitin, a fungal PAMP (Wan et al. 2004). The Arabidopsis MAP kinase 4 mutant, $m p k 4$, exhibits constitutive systemic acquired resistance (SAR) and resistance to virulent pathogens (Petersen et al. 2000). MPK4 was shown to interact with MKS1, a nuclear localized protein of unknown function, which can bind two WRKY TFs, namely AtWRKY25 and AtWRKY33 (Andreasson et al. 2005). MPK4 is capable of phosphorylating both MKS1 and the WRKY factors and it is hypothesized that MKS1 acts as a coupling protein, modulating the activities of the TFs in MPK4-mediated signaling.

Additional support for a role of WRKY factors in plant defense has come from computational analyses of microarrays to identify regulatory cis-acting DNA elements involved in defense gene activation. Applying clustering methods, several groups identified the WRKY factor binding site, referred to as the $\mathrm{W}$ box $\left(5^{\prime}-\mathrm{C} / \mathrm{TTGACC} / \mathrm{T}-3^{\prime}\right)$, often overrepresented within the promoters of coregulated Arabidopsis defense response genes (Andreasson et al. 2005; Maleck et al. 2000; Navarro et al. 2004; Petersen et al. 2000). W box elements are often also present within the promoters of $W R K Y$ genes and, in the case of parsley $P c W R K Y 1$, these elements were shown to mediate rapid PAMP-dependent activation of the gene (Eulgem et al. 1999) and to be target sites of WRKY factors in vivo (Turck et al. 2004).

Here, we report on the analysis of AtWRKY33 (At2g38470), the Arabidopsis orthologue of parsley PcWRKY1. We demonstrate that expression of AtWRKY33 is induced rapidly by pathogens and by endogenous defense signal molecules. Using transgenic plants carrying various AtWRKY33 promoter::GUS reporter constructs, as well as parsley protoplasts for transient expression assays, we show that this strong induced expression is dependent on a promoter region containing $\mathrm{W}$ box elements and that rapid pathogen- and PAMP-mediated activation of AtWRKY33 is highly dependent on these $\mathrm{W}$ box elements.

\section{RESULTS}

\section{Expression of AtWRKY33}

in plants and its response to UV-light and cycloheximide.

RNA blot analysis was performed using RNA derived from different tissues of the plant and from cultured Arabidopsis cells. AtWRKY33 expression was clearly detectable in mature green leaves, roots, shoots, and inflorescences (Fig. 1A). Little or no expression was observed at the seedling stage and in the siliques. However, the strong AtWRKY33 expression in mature leaves of plants grown in the greenhouse was not observed when the plants were grown under controlled aseptic conditions in a phytochamber (Fig. 1B), indicating that environmental factors or soil contaminations were partly responsible for the initially observed high expression levels. When seedlings grown in the dark were exposed to UV-containing white light, they showed high levels of AtWRKY33 transcript after $24 \mathrm{~h}$, indicating that light quality influences AtWRKY33 expression (Fig. 1C). This response was already detectable after 4 to $6 \mathrm{~h}$ of UV light treatment, albeit at rather low levels (compare Fig. 1C and D). Pretreatment of dark-grown Arabidopsis suspension cells for 30 min with the protein synthesis inhibitor cycloheximide $(\mathrm{CHX})$ resulted in a very rapid increase in AtWRKY33 transcript accumulation. This derepression suggests that AtWRKY33 expression is actively being suppressed by a negative regulator with a rather short half-life. This finding is consistent with recent wholegenome-array studies performed on plants treated with $\mathrm{CHX}$ (GEO Dataset GDS515) (Navarro et al. 2004).
Based on various prediction programs, the location of the AtWRKY33 protein has been reported to be the chloroplast (Mahalingam et al. 2005). However, nuclear localization of AtWRKY33 recently was demonstrated in transient assays employing the heterologous onion epidermal cell system (Zheng et al. 2006). Using AtWRKY33cDNA-GFP fusion constructs driven by the Cauliflower mosaic virus (CaMV) $35 \mathrm{~S}$ promoter for transient expression in Arabidopsis epidermal cells revealed consistent protein localization to the nucleus (Fig. 1E). Whether the protein also can reside in chloroplasts was not investigated.

\section{Induction of AtWRKY33}

by pathogens and by defense-signaling molecules.

Global expression data suggest that AtWRKY33 is induced under various abiotic and biotic stress conditions. We tested the response of this gene to two well-established endogenous signal molecules, namely salicylic acid (SA) and methyl jasmonate (MeJA). Exogenous application of SA to Arabidopsis seedlings already resulted in a rapid increase of AtWRKY33 mRNA $2 \mathrm{~h}$ post treatment (Fig. 2A). In contrast, MeJA treatment did not
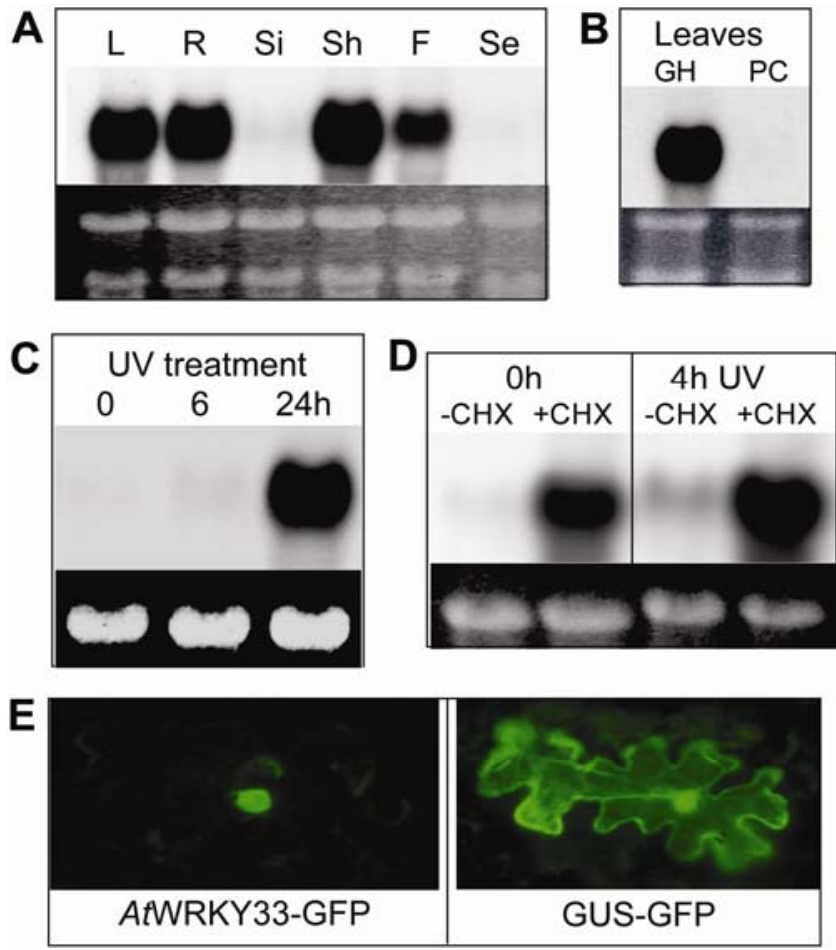

Fig. 1. Expression of AtWRKY33 and cellular localization of the protein. A, AtWRKY33 mRNA levels in different tissues of Arabidopsis greenhouse-grown plants. L, 4-week-old mature leaves; R, roots; $\mathrm{Si}$, siliques; Sh, shoots; F, flowers; Se, seedlings grown in the phytochamber. B, AtWRKY33 mRNA levels in mature leaves of plants grown in the greenhouse $(\mathrm{GH})$ and under aseptic conditions in a phytochamber (PC). C, Accumulation of AtWRKY33 mRNA in Arabidopsis-etiolated seedlings upon treatment with UV-containing white light for the time periods indicated. D, Accumulation of AtWRKY33 mRNA upon 30-min pretreatment of Arabidopsis-cultured suspension cells with cycloheximide (+CHX) and subsequent 4-h treatment with UV-containing white light. Blots from gels loaded with $20 \mu \mathrm{g}$ of total RNA per lane were hybridized with radioactively labeled $A t W R K Y 33 \mathrm{cDNA}$ and visualized by autoradiography in $\mathrm{C}$ and D. Ribosomal rRNA bands of the ethidium bromide-stained gels were used as control for equal loading in A to D. Nuclear localization of AtWRKY33-GFP fusion protein in E, Nuclear localilzation of AtWRKY33GFP fusion protin in Arabidopsis epidermal cells. Image using a green fluorescent protein (GFP) filter is shown for the AtWRKY33-GFP expression construct. As control construct $35 S:: G U S-G F P$ was used showing distribution of GUS-GFP protein within the cell. 
significantly increase AtWRKY33 mRNA levels (Fig. 2B). We next tested whether AtWRKY33 is induced when seedlings are challenged with the biotrophic oomycete pathogen Hyaloperonospora parasitica. Resistance toward this pathogen has been shown to be mediated via the SA-dependent defense signaling pathway (Glazebrook 2005). Arabidopsis ecotype Col-0 plants are resistant to the $H$. parasitica isolates Cala2 and Emoy2, whereas ecotype Ler-1 is resistant to the isolate Noks1. AtWRKY33 expression was induced in both ecotypes by the tested avirulent isolates (Fig. 3A to C). Increased AtWRKY33 transcript levels were detected readily within 2 to $4 \mathrm{~h}$ in Col- 0 seedlings challenged by the avirulent strains Cala2 and Emoy2 (Fig. 3A and B). The elevated level of AtWRKY33 transcript detected in the 10-h water control (Fig. 3B) was not consistently

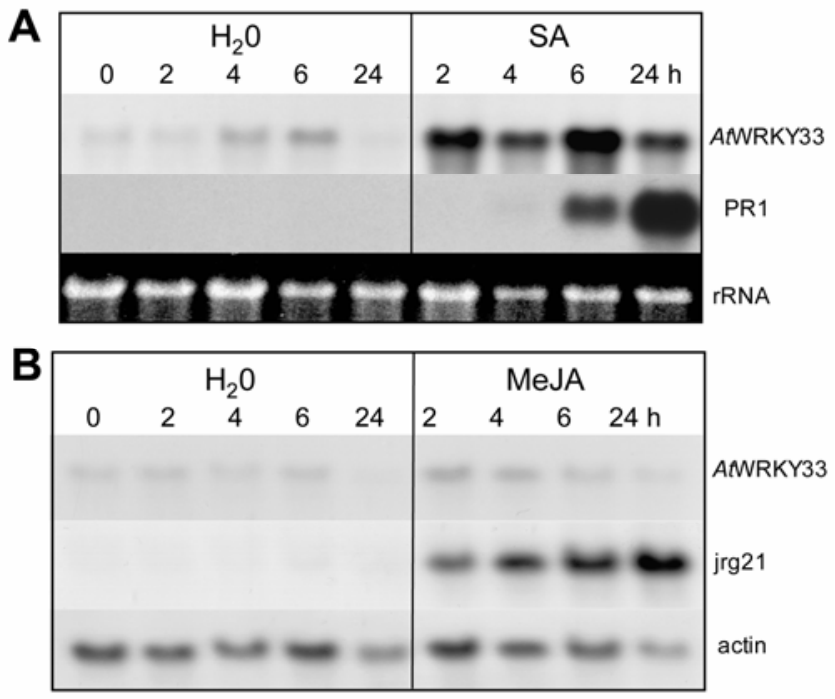

Fig. 2. AtWRKY33 is induced by salicylic acid (SA) but not by methyl jasmonate (MeJA). A, Arabidopsis seedlings were sprayed with $5 \mathrm{mM}$ SA or B, $45 \mu \mathrm{M}$ MeJA solution and total RNA extracted at the time periods indicated. Blots from gels loaded with $15 \mu \mathrm{g}$ of RNA per lane were hybridized with radioactively labeled $A t W R K Y 33$ and visualized by autoradiography. The same blots were re-hybridized with a $P R 1$ probe, a SA-responsive marker gene (A), or jrg21 cDNA representing an MeJA-induced gene (B). As controls for equal RNA loading, ribosomal rRNA of the ethidium bromide-stained gel (A) or hybridization with an actin cDNA (B) were used. observed and most likely was due to contamination of some plants in this sample. In Ler-1 seedlings challenged with the avirulent isolate Noks1, strong expression of AtWRKY33 was detected $12 \mathrm{~h}$ postinoculation (Fig. 3C). Expression of AtWRKY33 also was upregulated rapidly in seedlings infiltrated with avirulent or virulent bacterial $P$. syringae strains (data not shown), consistent with previous findings (Dong et al. 2003). Activation of AtWRKY33, however, was not observed in seedlings challenged by the barley pathogen Blumeria graminis f. $\mathrm{sp}$ hordei, to which Arabidopsis is a nonhost (Fig. 3D).

Although AtWRKY33 expression is strongly and positively affected by SA treatment, SA is not required for its activation by $H$. parasitica $\mathrm{Cala2}$, because transgenic Arabidopsis plants expressing the SA-degrading bacterial enzyme salicylate hydroxylase $(N a h G)$ responded in a way similar to wild-type plants (Fig. 4A). Cala2-dependent AtWRKY33 activation also was observed in seedlings of nprl mutant plants that also are affected in SA signaling downstream of SA (Fig. 4B). In contrast to this, Cala2-dependent expression of AtWRKY33 was dramatically delayed in pad4 mutant plants (Fig. 4C). The lipase-like protein PAD4 is a key upstream component of the SA-mediated signaling defense pathway (Glazebrook 2005). Mutant pad4 plants are susceptible to $H$. parasitica Cala2. This temporal delay in AtWRKY33 transcript accumulation also was observed in the Arabidopsis ecotype Ler-1, which is also highly susceptible to Cala2 (Fig. 4D). Application of SA to pad4 or Ler-1 seedlings resulted in a very rapid induction of AtWRKY33 expression (Fig. 4E) consistent with the position of $\mathrm{SA}$ in the signaling pathway downstream of PAD4.

\section{AtWRKY33 promoter regions mediating expression during defense signaling.}

In order to pinpoint regions of the AtWRKY33 promoter allowing activation of the gene during the plant defense response, we generated transgenic Arabidopsis Col-0 plants expressing the uidA (GUS reporter) gene under the control of AtWRKY33 promoters of varying length. The longest promoter fragment, designated P1, contained 1,230 bp of upstream sequence relative to the transcriptional start site (Supplementary Figure 1). Based on GUS activity staining of different tissues derived from transgenic plants carrying the AtWRKY33P1::GUS reporter construct, the P1 promoter proved sufficient to mediate the observed endogenous AtWRKY33 expression patterns

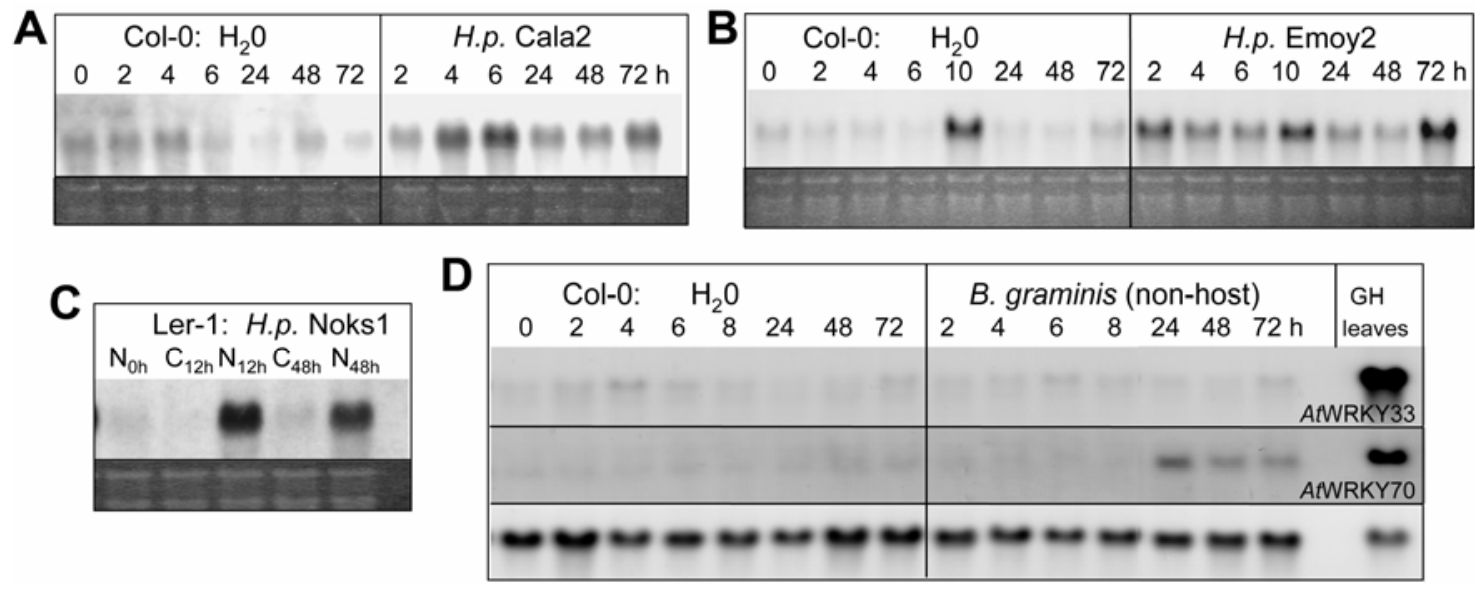

Fig. 3. Response of AtWRKY33 to pathogen challenge of Arabidopsis seedlings. A to C, Arabidopsis seedlings of the indicated ecotypes were sprayed with water or with the respective Hyaloperonospora parasitica (H.p.) isolates at $2 \times 10^{5}$ spores/ml and harvested at the indicated timepoints. N, Noks1. C, Untreated control. D, Col-0 Arabidopsis seedlings were treated with spores of the nonhost Blumeria graminis and harvested at the indicated timepoints. Blots from gels loaded with $10 \mu \mathrm{g}$ of total RNA per lane were hybridized with radioactively labeled $A t W R K Y 33 \mathrm{cDNA}$ or $A t W R K Y 70 \mathrm{cDNA}$ (positive control for B. graminis infection) and visualized by autoradiography. A to $\mathbf{C}$, Ribosomal rRNA bands of the ethidium bromide-stained gels or $\mathbf{D}$, hybridization with an actin probe served as controls for equal loading. The elevated senescence-dependent levels of AtWRKY33 and AtWRKY70 transcripts in leaves of 5-week-old greenhouse $(\mathrm{GH})$-grown plants are shown to the right. 
that were detected by RNA blot analyses (Fig. 5A). Moreover, in floral organs, it revealed a developmentally controlled spatial expression pattern for AtWRKY33 (Fig. 5A). No GUS staining was detected in young inflorescences or in anthers (Fig. 5A2 to 3). During further floral development, strong staining was observed in stigmatic papillae and the style (Fig. $5 \mathrm{~A} 3$ to 4$)$. At later stages post fertilization, GUS staining was restricted to the top part and to the abscission zone of fully elongated siliques (Fig. 5A5 to 6). In situ RNA hybridization experiments with longitudinal sections of siliques, including flower base and distal part of the petioles, revealed clear signals at the flower base around the abscission zones of the petals, sepals, and stamens (Fig. 5A7).

Wounding AtWRKY33P1::GUS plants, by cutting or squashing the cotyledons, locally activated the reporter gene (Fig. 5B). Exogenous spray application of SA or of the SA functional analog 2,6-dichloroisonicotinic acid (INA) also strongly induced expression of the reporter gene in the cotyledon assay (Fig. 5B). In contrast, spraying plants with MeJA did not result in an increase in GUS activity (data not shown; Fig. 5C), consistent with our RNA data (Fig. 2B) and demonstrating that this signal hormone does not induce AtWRKY33.

AtWRKY33P1::GUS plants challenged with spores of $H$. parasitica Cala2 showed a marked increase in GUS activity staining at and around infection sites (Fig. 5D1). A similar local activation of the reporter gene was observed in several independent transgenic lines and with different pathogens, including $P$. syringae DC3000 (virulent), P. syringae DC3000 carrying avrRpt4 (avirulent), Sclerotinia sclerotiorum (Fig. 5D2), Alternaria brassicicola (Fig. 5D3), Pythium sylvaticum (Fig. 5D4), and A. alternata (Fig. 6B) (AtWRKY33-P1::GUS). In the case of the root oomycete pathogen $P$. sylvaticum, massive GUS staining was observed primarily in secondary root initiation zones, secondary roots, and root hairs (Fig. 5D4).

Several independent F2 and F3 transgenic lines harboring different 5' AtWRKY33 promoter deletion-reporter gene constructs (Fig. 6A and Supplementary Figure 1, P1 to P6) were tested for their response to different pathogens. As an initial standard assay, we applied defined-sized droplets of $A$. brassicicola fungal mycelium suspensions onto leaves of the plants and assayed for GUS activity staining 5 and 6 days postinoculation (Fig. 6B). Strong, local, and very similar staining was observed around infection sites of all tested lines that harbored the P1, P2, P3, and P4 AtWRKY33 promoter reporter constructs (Fig. 6B; data not shown). In lines carrying the $\mathrm{P} 5$ construct, local responsiveness to A. brassicicola was still observed; however, GUS activity staining was significantly reduced and confined to fewer cells around the infection site (Fig. 6B). All these lines also were subsequently tested using $H$. parasitica Cala2, $P$. sylvaticum, and Pseudomonas syringae DC3000 ( \pm avrRpt4) and very similar results were obtained, with the exception that the P5 lines showed no clear GUS staining when challenged by $H$. parasitica Cala2 (data not shown). Thus, these results suggest that elements residing within the 38 -bp stretch at position -333 to -295 are responsible for mediating the strong pathogen-responsiveness of AtWRKY33, but that additional elements downstream of -295 also contribute. The 38-bp sequence contains two $\mathrm{W}$ box elements (W1 and W2) (Fig. 7A) known to mediate pathogen responsiveness of plant defense genes by interaction with WRKY TFs (Ülker and Somssich 2004). Interestingly, two similarly spaced functionally critical $\mathrm{W}$ box elements $\left(\mathrm{W}_{\mathrm{A} / \mathrm{B}}\right)$ also are present in the promoter of $P c W R K Y 1$, the parsley orthologue of AtWRKY33 (Fig. 7A) (Eulgem et al. 1999). Furthermore, an construct (Fig. 7B, P4 $4_{\mathrm{m} 1+2}$ ) significantly lowered overall GUS activity and elicitor-mediated inducibility to approximately four- to fivefold. Simultaneous mutation of W1, W2, and W3 (Fig.7B, P4 $4_{\mathrm{m} 1-3}$ ) nearly abolished overall PAMP inducibility, additional $\mathrm{W}$ box element (W3) embedded in DNA sequences similar to those found for the parsley $\mathrm{W}_{\mathrm{C}}$ element is present between positions -270 and -246 (Fig. 7A). This element or an additional $\mathrm{W}$ box at position -211 (W4) may be responsible for the weaker but clear pathogen responsiveness observed with the P5 transgenic lines. The pathogen responsiveness of the P5 transgenic lines was more obvious when bacterial suspensions of an avirulent strain of $P$. syringae DC3000 (+avrRpt4) were directly injected at high density into the apoplastic space of leaves via a needleless syringe (Supplementary Figure 2). In contrast to this, P6 transgenic lines showed no GUS activity staining above basal levels with any of the treatments used (Fig. 6B).

\section{PAMP-triggered responsiveness} of the AtWRKY33 promoter is mediated via $\mathrm{W}$ boxes.

Apart from two potential W boxes, database searches in PLACE or AtTFDB failed to reveal any other known cis-acting DNA elements implicated in defense gene activation within the $\mathrm{P} 5$ promoter. The functionality of the $\mathrm{W}$ boxes within the -333 AtWRKY33 promoter in PAMP-triggered activation was tested by transient expression assays employing the well-established parsley protoplast system and the oomycete-derived peptide Pep25 (Hahlbrock et al. 2003). PAMP-dependent activation of the reporter gene was observed with the AtWRKY33 P4 construct (Fig. 7B). Overall, this promoter was capable of 11fold elicitor-stimulated expression of the reporter gene. Mutating both upstream $\mathrm{W}$ boxes (W1 and W2; 5'-C/TTGAC

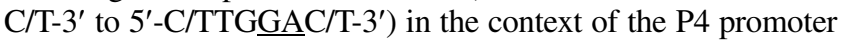
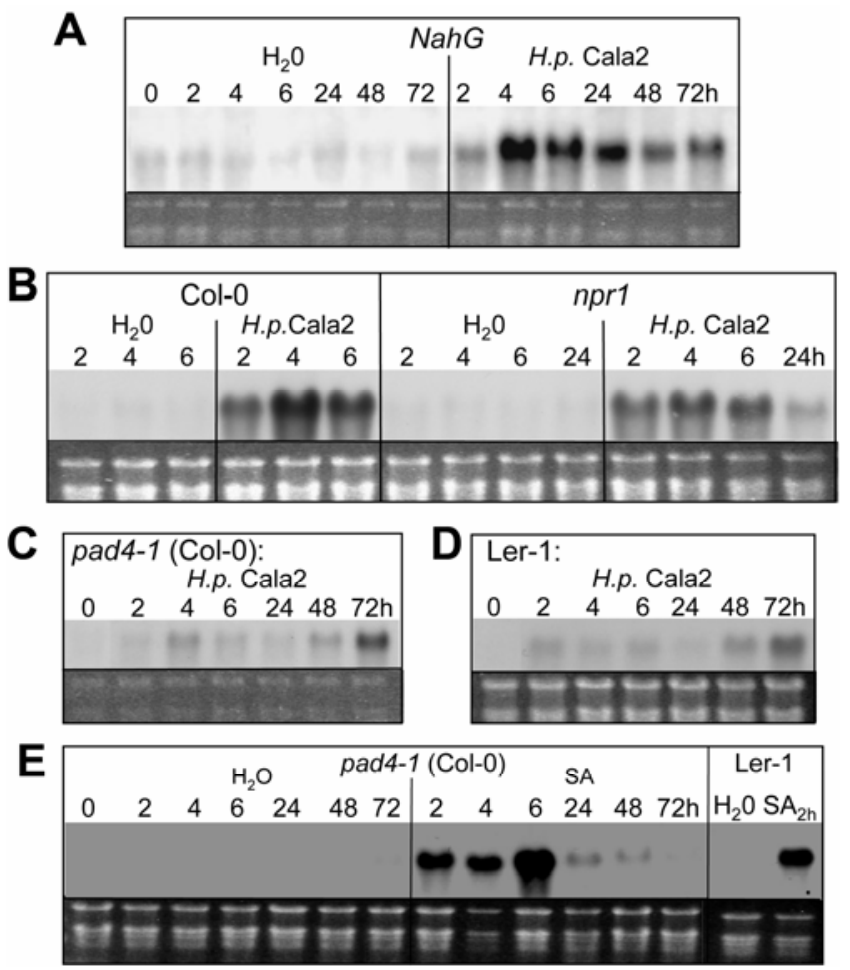

Fig. 4. Rapid activation of AtWRKY33 by Hyaloperonospora parasitica Cala2 does not require salicylic acid (SA) or NPR1 function but is dependent on PAD4. A through E, AtWRKY33 mRNA levels detected at the indicated timepoints from Arabidopsis A, NahG and B, Col-0 wild-type and npr 1 mutant seedlings sprayed with water or with $H$. parasitica Cala2 at 2 $\times 10^{5}$ spores/ml; Arabidopsis $\mathbf{C}$, pad4-1 and D, ecotype Ler-1 seedlings sprayed with $H$. parasitica Cala2 at $2 \times 10^{5}$ spores $/ \mathrm{ml}$; and $\mathbf{E}$, Arabidopsis pad4-1 and Ler-1 seedlings sprayed with water or with $5 \mathrm{mM}$ SA solution. Blots from gels loaded with $\mathbf{A}$ and $\mathbf{C}, 10$ or B, D, and E, $20 \mu \mathrm{g}$ of total RNA per lane were hybridized with radioactively labeled AtWRKY33 cDNA and visualized by autoradiography. Ribosomal rRNA bands of the ethidium bromide-stained gels served as controls for equal loading. 
suggesting a functional role of $\mathrm{W} 3$ in this response. The values obtained for $\mathrm{P} 4_{\mathrm{m} 1-3}$ were nearly identical to $\mathrm{P} 4_{\mathrm{m} 1-4}$ (Fig. 7B), in which the W4 element at position -211 also was mutated, indicating that $\mathrm{W} 4$ did not function as an independent $\mathrm{W}$ box element in these assays. Consistent with these results, GUS reporter gene expression driven by the shorter AtWRKY33 P5 fragment also showed PAMP inducibility with values similar to those of $\mathrm{P} 4_{\mathrm{m} 1+2}$ (Fig. 7B). Furthermore, mutations of $\mathrm{W} 3$ or $\mathrm{W} 3+\mathrm{W} 4$ in the context of the P5 construct yielded nearly identical GUS activity values and nearly no Pep25 inducibility $\left(\mathrm{P} 5_{\mathrm{m} 3}\right.$ and $\left.\mathrm{P} 5_{\mathrm{m} 3+4}\right)$ (Fig. 7B). Thus, PAMP-triggered activation of AtWRKY33 is mediated mainly by a set of three $\mathrm{W}$ box elements.

\section{Increased association of WRKY factors to the AtWRKY33 promoter upon benzothiadiazole $S$-methylester treatment.}

We used chromatin immunoprecipitation (ChIP) to determine if there is an increase in WRKY factor abundance associated with the AtWRKY33 promoter region encompassing the relevant $\mathrm{W}$ box elements upon activating plant defenses. Fragmented chromatin, isolated from Arabidopsis wild-type plants sprayed with benzothiadiazole $S$-methylester (BTH), a chemical inducer of systemic acquired resistance (Maleck et al. 2000), was immunoprecipitated using an anti-all-WRKY antibody that detects the majority of the WRKY factor family (Turck et al. 2004). Polymerase chain reaction (PCR) was performed on DNA before immunoprecipitation (INPUT) or on immunoprecipitated DNA using primers that amplify the -399 to -187 region of the AtWRKY33 promoter or, as a control, the AtWRKY33 open reading frame region spanning intron 1 (Fig. 7C). The ChIP experiment revealed a BTH-dependent in vivo increase in

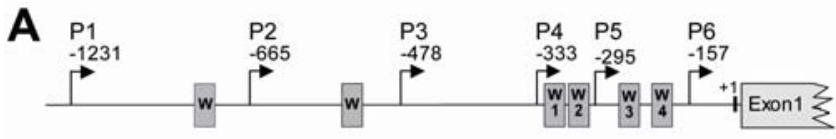

B

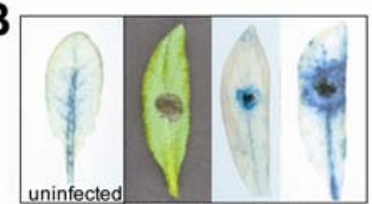

AtWRKY33-P1::GUS lines
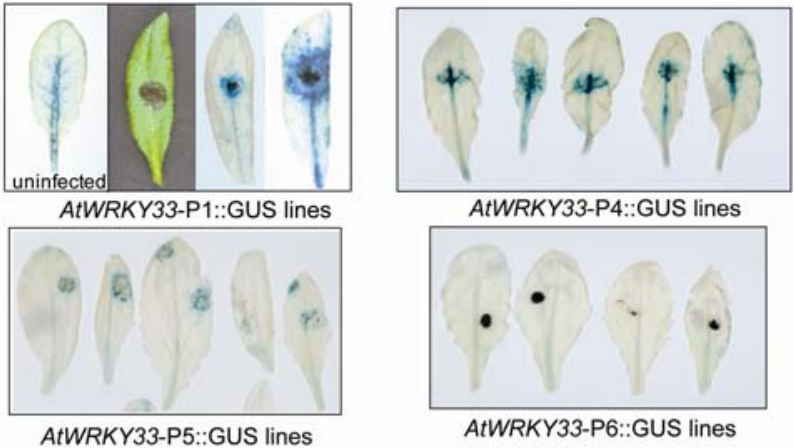

AtWRKY33-P4::GUS lines

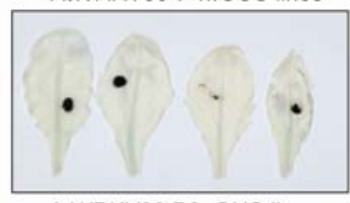

AtWRKY33-P6::GUS lines

Fig. 6. Pathogen-induced expression of the GUS reporter gene under the control of different derivatives of the AtWRKY33 promoter. A, Schematic diagram of the $5^{\prime}$ upstream region of the AtWRKY33 gene. Bent arrows marked with P1 to P6 represent the different 5' ends of the AtWRKY33 promoter used to generate transgenic Arabidopsis AtWRKY33::GUS expression lines. The transcription start site is marked with +1 , and the first exon indicated. Putative W box DNA elements are boxed and those relevant for this publication are marked W1 to W4. B, Histochemical GUS activity staining in leaves of different AtWRKY33promoter::GUS transgenic reporter lines challenged with Alternaria brassicicola or A. alternata (mid two leaves in b, AtWRKY33-P1::GUS lines). Fungal suspension was applied (25- to $50-\mu 1$ droplets per leaf) and staining performed 5 and 6 days postinoculation. Representative leaves from both T2 and T3 transgenic lines harboring the indicated AtWRKY33::GUS reporter constructs are shown. Three independent repetitions, each using leaves from several transgenic lines, were performed.
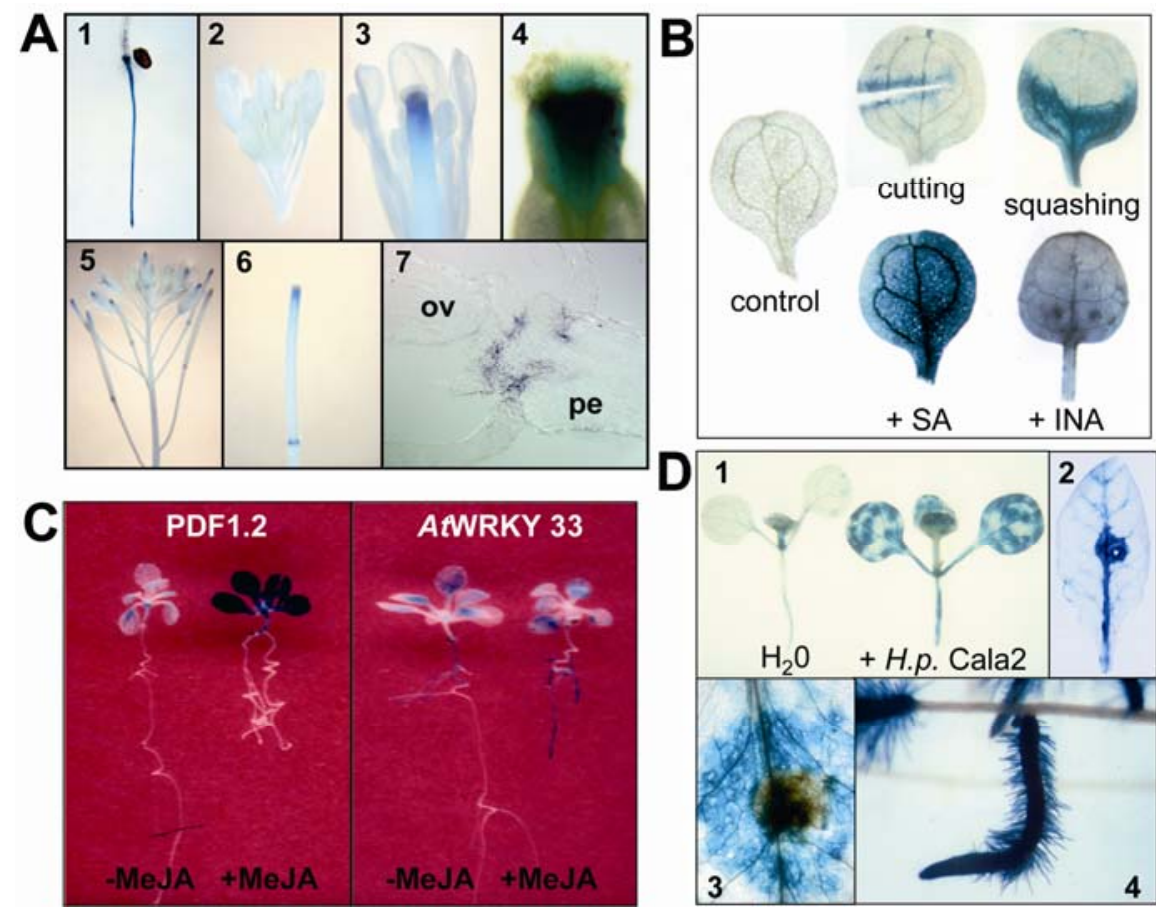

Fig. 5. Detection of GUS reporter gene expression driven by the 1.23-kb AtWRKY33 promoter in transgenic Arabidopsis plants. A, Histochemical localization of GUS activity of AtWRKY33::GUS transgenic plants in etiolated roots (1), young inflorescences and anthers (2 and 3), stigmatic papillae and the style (3 and 4), and floral abscission zones (5 and 6). AtWRKY transcripts (in situ hybridization) in sections made from siliques including flower base and distal part of petioles (7); ov, ovary; pe, petal. B, Histochemical localization of GUS activity detected in cotyledons of transgenic AtWRKY33::GUS reporter plants upon wounding or upon spraying with $5 \mathrm{mM}$ salicylic acid (SA) or $300 \mu \mathrm{M}$ 2,6-dichloroisonicotinic acid (INA) solution 6 h post treatment. C, Histochemical localization of GUS activity of transgenic AtWRKY33::GUS reporter lines grown on plates and sprayed with $45 \mu \mathrm{M}$ methyl jasmonate (MeJA). The transgenic line PDF1.2 contains the GUS reporter gene under the control of the nearly 1.2-kb-long PDF1.2a gene promoter and served as a positive control for jasmonic acid responsiveness. D, Histochemical localization of GUS activity of transgenic AtWRKY33::GUS reporter lines upon challenge of seedlings with Hyaloperonospora parasitica Cala2 (1), of fully expanded leaves with Sclerotinia sclerotiorum (2) and Alternaria brassicicola (3), and of roots with Pythium sylvaticum (4). 
WRKY factors associated with the promoter region. However, it also showed that there is already significant WRKY protein binding to this DNA region in untreated leaf tissue, which is in agreement with previous findings that $\mathrm{W}$ box elements often are constitutively occupied by WRKY TFs (Turck et al. 2004).

\section{DISCUSSION}

Global expression profiling has confirmed that pathogentriggered activation of plant defenses is associated with massive transcriptional reprogramming (Eulgem 2005). Many of the class of "immediate-early" type genes in this program, whose transcriptional activation does not require de novo protein biosynthesis, encode for TFs important in regulating the defense transcriptome. Several genes of the WRKY TF family belong to this class, including AtWRKY33. Based on microarray data, expression of AtWRKY33 is rapidly and strongly induced by PAMPs such as the bacterial flagellin-derived peptide flg22 (Navarro et al. 2004) and by chitin, a structural element of fungal walls (Wan et al. 2004). It also is induced by avirulent strains of $P$. syringae (Bartsch et al. 2006), by $\mathrm{H}_{2} \mathrm{O}_{2}$, and by ozone oxidative stress (Davletova et al. 2005; Mahalingam et al. 2005).

Our results illustrate that AtWRKY33 expression also is induced rapidly by various other pathogens, including avirulent and virulent races of the biotrophic oomycete $H$. parasitica, by the necrotrophic fungi A. brassicicola, A. alternata, and S. sclerotiorum, and by the root oomycete Pythium sylvaticum. Additionally, AtWRKY33 responds in seedlings to wounding and rapidly to exogenous application of SA, INA, and BTH, but not to
MeJA. A. brassicicola-dependent expression of AtWRKY33 is not affected in the jasmonic acid (JA)-insensitive mutant jarl (Staswick et al. 2002), further indicating that JA or MeJA signaling is not required for its expression (data not shown). Still, $H$. parasitica-mediated AtWRKY33 expression does not require SA for its activation, as demonstrated by its unaltered response to this pathogen in NahG plants. Similarly, pathogen-induced expression of AtWKRY33 was mostly unaffected in nprl plants, suggesting that signaling components downstream of SA also are not needed. However, rapid $H$. parasitica-induced expression of AtWRKY33 expression does require PAD4 function. In Arabidopsis ecotype Col-0, resistance toward $H$. parasitica Cala2 is determined by the major resistance (R) gene $R P P 2$ (Aarts et al. 1998). RPP2-dependent resistance has been shown to require $P A D 4$, an important regulator upstream of SA signaling (Glazebrook et al. 1997). Our results indicate, however, that activation of AtWRKY33 expression by $H$. parasitica Cala 2 occurs within an SA-independent signaling pathway downstream of PAD4. This additional pathway appears also to be $R P P 2$ dependent, because a similar strong temporal delay in $H$. parasitica Cala2-induced AtWRKY33 expression is observed in pad4 mutants and in wild-type susceptible Ler-1 plants that lack $R P P 2$. The existence of both SA-dependent and SA-independent pathways linked to the two key interacting regulators EDS1 and PAD4 recently has been demonstrated (Bartsch et al. 2006). In tobacco, activation of an early Tobacco mosaic virus-responsive WRKY gene TIZZ also was shown to occur through an SA-independent defense signaling pathway (Yoda et al. 2002).

Intriguingly, the biotrophic barley powdery mildew pathogen $B$. graminis did not activate AtWRKY33 whereas the ne-

A
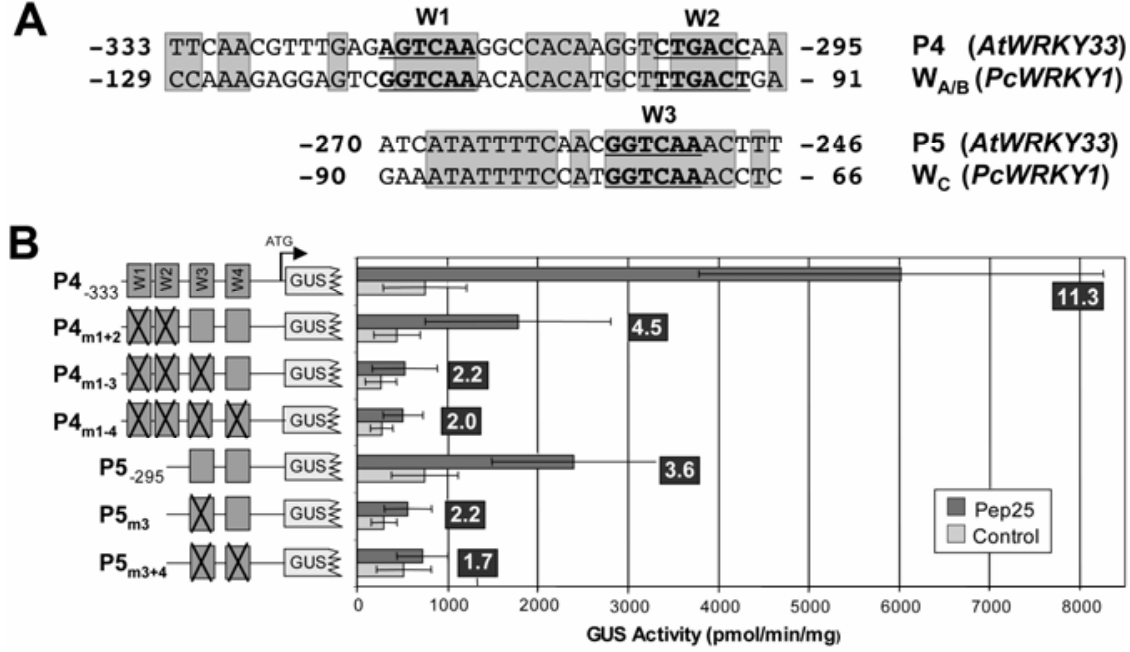

C

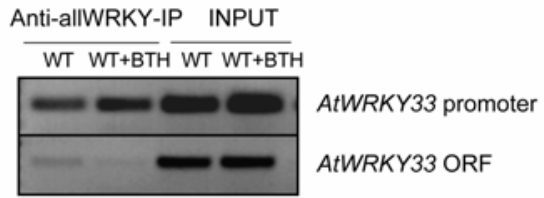

Fig. 7. W box elements mediate pathogen-associated molecular pattern (PAMP)-triggered transient expression of the AtWRKY33 promoter-driven GUS reporter gene in parsley protoplasts. A, Detailed comparison of the $5^{\prime}$ regulatory regions that share sequence similarity between the Arabidopsis AtWRKY33 gene and its parsley orthologue PcWRKY1 (Eulgem et al. 1999). Sequence numberings are based on their positions within their respective gene promoters relative to the transcription start site. B, Transient transfection assays in parsley protoplasts. Protoplasts were transfected with the different AtWRKY33 promoter::GUS translational fusion constructs schematically shown on the left, and either left untreated (control) or treated with the oomycete-derived PAMP polypeptide Pep25 for 8 h. The average specific GUS activities along with their standard deviation for each construct \pm Pep 25 are given. Mutations of the respective W box element (5'C/TTGACC/T3' to 5'C/TTGGAC/T) are marked by a bold X in the left-hand scheme. Specific GUS activities (bars) and the values for fold elicitor inducibility (boxed numbers) each represent the means from 10 measurements derived from five independent transfection experiments. C, Chromatin immunoprecipitation (ChIP) was conducted using the anti-all-WRKY serum (Turck et al. 2004) on extracts from untreated and 6-h benzothiadiazole S-methylester (BTH)-treated Arabidopsis wild-type leaves. Polymerase chain reaction (PCR) was performed using primers spanning the -399 to -187 region of the AtWRKY33 promoter or spanning intron 1 of the AtWRKY33 open reading frame (ORF). INPUT represents PCR products from the same tissue extracts following formaldehyde crosslinking but not subjected to immunoprecipitation. 
crotroph A. alternata did. Arabidopsis is nonhost to these two pathogens and, in both cases, hyphal growth appears to be arrested at a similar early penetration stage (Narusaka et al. 2005; Zimmerli et al. 2004). Although not completely comparable, the microarray data that were performed on plants challenged with these two pathogens did reveal differences in the nonhost plant resistance responses. Most notable was the finding that $B$. graminis induced expression of some prominent marker genes of the JA/ethylene (ET) signaling pathway, whereas expression of these genes was unaffected upon $A$. alternata infection (Narusaka et al. 2005; Zimmerli et al. 2004). Because the JA/ET and SA signaling pathways can be antagonistic (Glazebrook 2005), activation of part of the JA pathway by $B$. graminis may have a negative effect on some component within the signaling pathway downstream of PAD4 that is required for triggering AtWRKY33 expression.

A recent publication by Zheng and associates (2006) that appeared after submission of our work confirmed the importance of AtWRKY33 in plant defense. Two Atwrky33 loss-offunction mutants showed enhanced susceptibility toward Botrytis cinerea and A. brassicicola, whereas ectopic overexpression of AtWRKY33 increased resistance toward these fungi but compromised basal resistance to Pseudomonas syringae DC3000 bacteria. Interestingly, however, the Atwrky33 mutants did not differ in their response to this bacterial strain when compared with wild-type plants. The authors conclude from their study that AtWRKY33 acts as a positive regulator of JA- and ET-mediated defense signaling but as a negative regulator of SA-mediated responses. They note that pathogen-induced expression of AtWRKY33 does not require the signaling molecule SA, a finding that is in complete agreement with our data.

Functional dissection of the AtWRK33 promoter revealed that three closely spaced $\mathrm{W}$ box elements are the key enhancers mediating the observed rapid pathogen- or PAMP-triggered activation of transcription. Together with our in vivo findings demonstrating stimulus-dependent enrichment of WRKY factors at this promoter, this strongly implicates WRKY factors as the main regulatory proteins in modulating expression of this gene under biotic stress conditions. W box motifs commonly are detected within the promoters of coregulated Arabidopsis defense response genes, implying that WRKY factors play a major role in their regulation (Ülker and Somssich 2004). Reporter gene constructs driven by W box elements in transgenic Arabidopsis plants were strongly activated by diverse pathogens (Rushton et al. 2002). A W-boxcontaining element termed E17-27 was identified in the parsley $C M P G 1$ promoter that enabled immediate elicitor-induced reporter gene expression in transient assays and pathogen-triggered expression in transgenic Arabidopsis plants (Kirsch et al. 2001). An element highly similar to E17-27, present in the Arabidopsis CMPG1 promoter, mediated rapid pathogen responsiveness of a reporter gene in transgenic Arabidopsis plants (Heise et al. 2002). AtCMPG1 recently was shown to be required for activation of defense mechanisms triggered by resistance genes in tobacco and tomato (Gonzalez-Lamothe et al. 2006). Other defense-associated genes for which the involvement of $\mathrm{W}$ box elements in their activation has been functionally demonstrated include Arabidopsis NPRI (Yu et al. 2001), AtTRXh5 (Laloi et al. 2004) and SIRK/FRK1 (Asai et al. 2002; Robatzek and Somssich 2002), Brassica oleracea SFR2 (Rocher et al. 2005), maize PRms (Raventós et al. 1995), some parsley PcPR10 genes (Rushton et al. 1996), and tobacco CHN48 (Yamamoto et al. 2004).

Like AtWRKY33, many pathogen-induced Arabidopsis $W R K Y$ genes contain multiple $\mathrm{W}$ box elements within their $5^{\prime}$ regulatory regions (Dong et al. 2003), suggesting that they are under positive or negative feedback regulation. In the case of
PcWRKY1, the parsley orthologue of AtWRKY33, ChIP analyses revealed elicitor-dependent and transient in vivo binding of parsley $P c \mathrm{WRKY} 1$ to three closely spaced $\mathrm{W}_{\mathrm{A} / \mathrm{B} / \mathrm{C}}$ elements within the promoter of $P c W R K Y 1$ (Turck et al. 2004). In addition, the palindromically arranged $\mathrm{W}_{\mathrm{A} / \mathrm{B} / \mathrm{C}}$ boxes were shown to be responsible for the particularly rapid response of PcWRKY1 to the PAMP Pep-25 (Eulgem et al. 1999). A similar structural organization of three functionally important $\mathrm{W}$ box elements (W1, W2, and W3) also is present in the AtWRKY33 promoter (Fig. 7A). Although the spacing of $\mathrm{W} 3$ relative to $\mathrm{W} 1$ and $\mathrm{W} 2$ in the AtWRKY33 promoter is larger than between the $\mathrm{W}_{\mathrm{A} / \mathrm{B} / \mathrm{C}}$ elements of PcWRKY1, W1 and the parsley $\mathrm{W}_{\mathrm{C}}$ elements both appear embedded in a similar DNA sequence environment (Fig. 7A). Whether this is purely fortuitous or whether it's indicative of a DNA domain that is targeted by common regulatory components remains to be addressed. Although intense database searches have not revealed the presences of additional cis-acting DNA elements within the decisive AtWRKY33 promoter region, we nevertheless cannot completely exclude a contribution of other unknown elements in modulating pathogen-dependent expression of the gene. Still, our data strongly favor the hypothesis that WRKY factors acting via W box binding are the major regulators of AtWRKY33. Because activation of $A t W R K Y 33$ occurs independent of de novo protein synthesis, such factors should be present in unchallenged cells and should be post-translationally regulated upon pathogen stimuli, a situation reminiscent of the one observed for PcWRKY1 activation in parsley (Turck et al. 2004).

Key questions that need to be addressed include identifying the signal molecule or molecules required for pathogeninduced activation of AtWRKY33 transcription, pinpointing the WRKY factors responsible for the rapid and transient $\mathrm{W}$ boxdependent activation of AtWRKY33, determining whether these WRKY factors are identical to or are part of the negative regulators controlling AtWRKY33 as inferred from the protein synthesis inhibitor studies, and discovering what post-translational modifications they undergo upon pathogen challenge of the cell. Finally, elucidation of the direct AtWRKY33 target genes will be of utmost importance and should reveal vital clues to our understanding of the pathways controlled by this TF.

\section{MATERIALS AND METHODS}

\section{Plants, cell suspension culture, and growth conditions.}

Arabidopsis thaliana ecotype Col-0 and Ler-1 plants, NahG plants (Gaffney et al. 1993), ndrl (Century et al. 1997), nprl (Cao et al. 1997), and pad4-1 (Glazebrook et al. 1997) mutants, and PDF1.2::GUS transgenic lines were used in this study. The plants were grown on double-autoclaved soil in phytochambers (Percival Scientific, Boone, IA, U.S.A.) for most purposes under short-day conditions ( $8 \mathrm{~h}$ of light and 16 h of dark) at $20^{\circ} \mathrm{C}$. A. thaliana (ecotype Col-0, line At7) cells were propagated in continuous darkness as previously reported (Trezzini et al. 1993).

\section{Treatment of plants or cultured cells with SA, INA, MeJA, CHX, UV-light, and wounding.}

For INA, MeJA, and SA treatment, 10- to 14-day-old seedlings were sprayed individually with solutions containing either $5 \mathrm{mM} \mathrm{Na}$-salicylate $+0.02 \%$ (vol/vol) Silwet L-77 (Lehle Seeds, Round Rock, TX, U.S.A.), $45 \mu \mathrm{M}$ MeJA in water, or a $0.59-\mathrm{mg} / \mathrm{ml}(300 \mu \mathrm{g})$ solution of INA in water for the indicated time periods. Control plants were sprayed with water or water containing $0.02 \%$ Silwet L-77. For UV illumination of Arabidopsis cells, four TL $18 \mathrm{~W} / 29$ bulbs (warm white light; Philips Licht, Hamburg, Germany), three TL18W/18 blue bulbs (Philips) and two Sylvania blacklight blue bulbs (OSRAM Sylvania, 
München, Germany) were employed in a dark phytochamber at $26^{\circ} \mathrm{C}$. CHX $(20 \mu \mathrm{M})$ was added to dark-grown cell cultures 30 min prior to UV-light treatment.

For the plate assays shown in Figure 5C, seeds were germinated and kept on 0.5 Murashige-Skoog (MS) plates containing $4.5 \mu \mathrm{M}$ MeJA.

\section{Treatment of plants with pathogens.}

H. parasitica Emoy 2 and Cala2 were provided by E. Holub (Warwick HRI, Wellesbourne, England), Noks1 was provided by E. Kombrink and J. Ehlting, (Max Planck Institut für Züchtungsforschung [MPIZ], Köln, Germany), and Blumeria graminis f. sp. hordei by V. Lipka (MPIZ). Pathogen challenge inoculations were conducted by spraying the seedlings (10 to 14 days old) or plant leaves with an $H$. parasitica spore suspension $\left(2 \times 10^{5}\right.$ spores $/ \mathrm{ml}$ in $\mathrm{H}_{2} \mathrm{O}$ containing $10^{-6} \%$ [vol $/ \mathrm{vol}$ ] Tween 20) or by dispersing B. graminis spores on the leaves.

$P$. syringae pv. tomato strain DC3000 ( \pm avrRpt4) was infiltrated into leaves at $10^{8} \mathrm{CFU} \mathrm{ml}{ }^{-1}$ in $10 \mathrm{mM} \mathrm{MgCl}_{2}$.

Alternaria brassicicola strain MUCL20297 (Broekaert et al. 1990) was grown for 1 week in potato dextrose (PD) liquid culture under agitation at $28^{\circ} \mathrm{C}$. The mycelium subsequently was homogenized by an Ultra-thurax or Polytron and 25- to $50-\mu 1$ droplets of fungal suspension were applied per leaf depending on their size. A. alternata and Pythium sylvaticum were obtained from DSMZ, the German National Resource Centre for Biological Material (Braunschweig, Germany), and S. sclerotiorum was kindly provided by W. Gieffers (MPIZ). Growth conditions of $S$. sclerotiorum were at $25^{\circ} \mathrm{C}$ in PD liquid media under slow agitation on a shaker. The mycelium was processed as describe for Alternaria spp. above.

\section{RNA isolation and analysis.}

Plant material was ground in liquid $\mathrm{N}_{2}$, and RNA was isolated using the RNA/DNA Maxi Kit (Qiagen, Hilden, Germany) or TRIZOL-reagent (Invitrogen, Karlsruhe, Germany) according to the manufacturer's instructions. In all, 10 to 20 $\mu \mathrm{g}$ was used for RNA blot analysis using standard molecular procedures (Sambrook et al. 1989). DNA probes were radioactively labeled by random priming using $\left[\alpha-{ }^{32} \mathrm{P}\right] \mathrm{dCTP}$ and the Ready-To-Go Kit (Amersham Pharmacia Biotech, Freiburg, Germany) according to the manufacturer's instructions.

\section{Construction of transgenes and generation of transgenic plants.}

For each reporter construct, the relevant AtWRKY33 promoter containing the 5' ATG upstream regions, 1,248 bp (P1), 682 bp (P2), 495 bp (P3), 350 bp (P4), 312 bp (P5), and 174 bp (P6), were amplified by PCR and introduced into the HindIII-BamHI sites of pUC9-GUS (van de Löcht et al. 1990). The entire promoter-GUS cassette than was excised from the vector and cloned into the binary Ti vector pGPTV (Becker et al. 1992), replacing the endogenous GUS cassette. Col-0 plants were transformed using the floral-dip method (Clough and Bent 1998) and the Agrobacterium tumefaciens GV3101 (Koncz et al. 1994). The PDF1.2::GUS transgenic line contained 1,178 bp of promoter sequence of the PDF1.2a gene (At5g44420) and was generated as described for the AtWRKY33 promoter reporter constructs above.

\section{Transient transfection experiments.}

The AtWRKY33 P4 and P5 DNA fragments in the pUC9GUS reporter vector were used for transient expression analyses with parsley cell culture protoplasts as previously described (van de Löcht et al. 1990). The $\mathrm{P}_{\mathrm{m} 1-4}$ and $\mathrm{P} 5_{\mathrm{m} 3-4}$ promoter constructs (Fig. 6B) in which the core sequence of the respective $\mathrm{W}$ box, 5'-TGAC-3', was altered by a 2-bp block mutation to
5'-TGGA-3', was achieved by the PCR-based megaprimer method (Landt et al. 1990). In each assay, $2 \times 10^{6}$ protoplasts were transfected with $5 \mu \mathrm{g}$ of GUS reporter plasmid linearized with ScaI. PAMP treatment was carried out with Pep-25 at 333 $\mathrm{ng} / \mathrm{ml}$ originally derived from the cell wall of the oomycete Phytophthora sojae (Nürnberger et al. 1994). Suspensions of transfected protoplasts were split, and one-half was treated for $8 \mathrm{~h}$ with the elicitor while the other half remained untreated. Aliquots subsequently were harvested and treated as described previously (Rushton et al. 1996).

For transient expression in single cells, the AtWRKY33 cDNA was cloned into the Gateway destination vector pPAMKAN-35S-GWY-GFP according to the protocol provided by Invitrogen. This allowed the generation of an N-terminal fusion protein to green fluorescent protein (GFP). The control GFP construct was made by deletion of the Gateway cassette, resulting in a vector expressing GFP directly from the $35 \mathrm{~S}$ CaMV promoter. These constructs were used to bombard leaves of leek and 3-week-old Arabidopsis Col-0 plants. DNA coating of gold particles and bombardments were performed as previously described (Panstruga et al. 2003). To allow for protein accumulation, the bombarded leaves were placed in a light chamber at $18^{\circ} \mathrm{C}$ for $20 \mathrm{~h}$ prior to analysis by fluorescence microscopy using a Zeiss Axiophot 1 (Carl Zeiss, Jena, Germany) and appropriate filters for GFP (excitation: 470/40; emission: 525/50). Fluorescence and brightfield micrographs were taken with a digital imaging system (Diskus, Technisches Büro Hilgers, Königswinter, Germany).

\section{Chromatin immunoprecipitation.}

Col-0 wild-type and pad4.1 plants were grown for 28 days on MS media plates under long-day conditions. Plants were sprayed with BTH solution $(126 \mathrm{mg} / \mathrm{liter}=300 \mu \mathrm{M})$ and harvested together with untreated control plants after $6 \mathrm{~h}$. Wholeplant material ( $2 \mathrm{~g}$ per assay) was processed for chromatin immunoprecipitation according to the protocol of Gendrel and associates (2005) and using the previously described anti-all WRKY serum (Turck et al. 2004). The final immunoprecipitated DNA was resuspended in $50 \mu \mathrm{l}$ of Tris-EDTA buffer and $1.5 \mu \mathrm{l}$ was used for PCR amplification in the presences of $0.3 \mu \mathrm{M}$ each primer, $200 \mu \mathrm{M}$ deoxynucleotide triphosphate, and Taq polymerase (Ampliqon) for 33 cycles of 94,58 , and $72^{\circ} \mathrm{C}$ steps with $30 \mathrm{~s}$ at each temperature. The primer pair 5'-ATCATACGTGTC AGAACGAGACAT-3' and 5'-TTCGTTTTTATTTTTAGGGTC ACA-3' was used to amplify 212 bp of the AtWRKY33 promoter region encompassing the W box DNA elements. Primer pair 5'CTCCTTCTCTTGTCTCTCCTTCC-3' and 5'-TTGTGATTAA AGCTCCTGTGGTT-3' was used to amplify 368 bp of the AtWRKY33 open reading frame spanning intron 1.

\section{GUS staining.}

Histochemical staining of plant tissue was performed by vacuum infiltration (three times for 1 to $2 \mathrm{~min}$ each) with $\mathrm{X}$ gluc solution $\left(100 \mathrm{mM} \mathrm{NaPO}_{4}, 2 \mathrm{mM} \mathrm{K}{ }_{3} \mathrm{Fe}(\mathrm{CN})_{6}, 0.1 \%\right.$ Triton$\mathrm{X}-100$, and $\mathrm{X}$-gluc at $0.5 \mathrm{mg} / \mathrm{ml}$ ) followed by incubation at $37^{\circ} \mathrm{C}$ overnight, and subsequent destaining of the tissue for several days in $70 \%$ ethanol.

\section{In situ RNA hybridization.}

In situ hybridization was performed according to Fletcher and associates (1999). Briefly, tissue pieces, including half of the siliques and the distal part of the petioles, were harvested and fixed in $4 \%$ formaldehyde for $4 \mathrm{~h}$ on ice. After dehydration in a graded series of ethanol, the tissue was embedded in paraffin. Longitudinal semithin sections were prepared and hybridized in situ with digoxigenin-labeled sense and antisense transcripts. Signal development was by using anti-digoxigenin alkaline 
phosphatase. Micrographs were taken using a Zeiss Axiophot 1 microscope and DIC optics and a digital imaging system (Diskus, Technisches Büro Hilgers, Königswinter, Germany).

\section{DNA sequencing.}

The correctness of all reported DNA constructs was determined by the MPIZ DNA core facility ADIS using BigDye terminator chemistry on Applied Biosystems 377 sequencers. Oligonucleotides were purchased from GIBCO (Life Technologies, Gaithersburg, MD, U.S.A.).

\section{ACKNOWLEDGMENTS}

We thank S. Heppelmann, and N. Kamphaus for excellent technical assistance, S. Bau for providing the jrg21 probe, B. Ülker for providing the pPAM-KAN-35S-GWY-GFP expression vector, and $\mathrm{M}$. Barth and $\mathrm{M}$. Kalde for providing RNA blots. This work was partly supported by the Deutsche Forschungsgemeinschaft funding of the Graduiertenkolleg IIIGK-GRK 306/1 and the AFGN Grant SO235/5-1/2.

\section{LITERATURE CITED}

Aarts, N., Metz, M., Holub, E., Staskawicz, B. J., Daniels, M. J., and Parker, J. E. 1998. Different requirements for EDS1 and NDR1 by disease resistance genes define at least two $R$ gene-mediated signaling pathways in Arabidopsis. Proc. Natl. Acad. Sci. U.S.A. 95:10306-10311.

Andreasson, E., Jenkins, T., Brodersen, P., Thorgrimsen, S., Petersen, N. H. T., Zhu, S., Qiu, J.-L., Micheelsen, P., Rocher, A., Petersen, M., Newman, M.-A., Nielsen, H. B., Hirt, H., Somssich, I., Mattsson, O., and Mundy, J. 2005. The MAP kinase substrate MKS1 is a regulator of plant defense responses. EMBO (Eur. Mol. Biol. Organ.) J. 24:2579-2589.

Asai, T., Tena, G., Plotnikova, J., Willmann, M. R., Chiu, W.-L., GomezGomez, L., Boller, T., Ausubel, F. M., and Sheen, J. 2002. MAP kinase signaling cascade in Arabidopsis innate immunity. Nature 415:977-983.

Bartsch, M., Gobbato, E., Bednarek, P., Debey, S., Schultze, J. L., Bautor, J., and Parker, J. E. 2006. Salicylic acid-independent ENHANCED DISEASE SUSCEPTIBILITY1 signaling in Arabidopsis immunity and cell death is regulated by the monooxygenase FMO1 and the nudix hydrolase NUDT7. Plant Cell 18:1038-1051.

Becker, D., Kemper, E., Schell, J., and Masterson, R. 1992. New plant binary vector with selectable markers located proximal to the left T-DNA border. Plant Mol. Biol. 20:1195-1197.

Broekaert, W. F., Terras, F. R. G., Cammue, B. P. A., and Vanderleyden, J. 1990. An automated quantitative assay for fungal growth inhibition. FEMS (Fed. Eur. Microbiol. Soc.) Microbiol. Lett. 69:55-60.

Cao, H., Glazebrook, J., Clarke, J. D., Volko, S., and Dong, X. 1997. The Arabidopsis NPRl gene that controls systemic acquired resistance encodes a novel protein containing ankyrin repeats. Cell 88:57-63.

Century, K. S., Shapiro, A. D., Repetti, P. P., Dahlbeck, D., Holub, E., and Staskawicz, B. J. 1997. NDR1, a pathogen-induced component required for Arabidopsis disease resistance. Science 278:1963-1965.

Clough, S. J., and Bent, A. F. 1998. Floral dip: A simplified method for Agrobacterium-mediated transformation of Arabidopsis thaliana. Plant J. 16:735-743.

Cormack, R. S., Eulgem, T., Rushton, P. J., Köchner, P., Hahlbrock, K., and Somssich, I. E. 2002. Leucine zipper containing WRKY proteins widen the spectrum of immediate early elicitor-induced WRKY transcription factors in parsley. Biochim. Biophys. Acta 1576:92-100.

Davletova, S., Schlauch, K., Coutu, J., and Mittler, R. 2005. The zinc-finger protein Zat12 plays a central role in reactive oxygen and abiotic stress signaling in Arabidopsis. Plant Physiol. 139:847-856.

Deslandes, L., Olivier, J., Theulières, T., Hirsch, J., Feng, D. X., BittnerEddy, P., Beynon, J., and Marco, Y. 2002. Resistance to Ralstonia solanacearum in Arabidopsis thaliana is conferred by the recessive RRS1$R$ gene, a member of a novel family of resistance genes. Proc. Natl. Acad. Sci. U.S.A. 99:2404-2409.

Dong, J., Chen, C., and Chen, Z. 2003. Expression profiles of the Arabidopsis WRKY gene superfamily during plant defense response. Plant Mol. Biol. 51:21-37.

Eulgem, T. 2005. Regulation of the Arabidopsis defense transcriptome. Trends Plant Sci. 10:71-78.

Eulgem, T., Rushton, P. J., Schmelzer, E., Hahlbrock, K., and Somssich, I. E. 1999. Early nuclear events in plant defense: Rapid gene activation by WRKY transcription factors. EMBO (Eur. Mol. Biol. Organ.) J. 18:4689-4699.

Eulgem, T., Rushton, P. J., Robatzek, S., and Somssich, I. E. 2000. The
WRKY superfamily of plant transcription factors. Trends Plant Sci. 5:199-206.

Fletcher, J. C., Brand, U., Running, M. P., Simon, R., and Meyerowitz, E. M. 1999. Signaling of cell fate decisions by CLAVATA3 in Arabidopsis shoot meristems. Science 283:1911-1914.

Gaffney, T., Friedrich, L., Vernooij, B., Negrotto, D., Nye, G., Uknes, S., Ward, E., Kessmann, H., and Ryals, J. 1993. Requirement of salicylic acid for the induction of systemic acquired resistance. Science 261:754-756.

Gendrel, A.-V., Lippman, Z., Martienssen, R., and Colot, V. 2005. Profiling histone modification patterns in plants using genomic tiling microarrays. Nat. Methods 2:213-218.

Glazebrook, J. 2005. Contrasting mechanisms of defense against biotrophic and necrotrophic pathogens. Annu. Rev. Phytopathol. 43:205-227.

Glazebrook, J., Zook, M., Mert, F., Kagan, I., Rogers, E. E., Crute, I. R., Holub, E. B., Hammerschmidt, R., and Ausubel, F. M. 1997. Phytoalexin-deficient mutants of Arabidopsis reveal that PAD4 encodes a regulatory factor and that four $P A D$ genes contribute to downy mildew resistance. Genetics 146:381-392.

Gonzalez-Lamothe, R., Tsitsigiannis, D. I., Ludwig, A. A., Panicot, M., Shirasu, K., and Jones, J. D. G. 2006. The U-Box protein CMPG1 is required for efficient activation of defense mechanisms triggered by multiple resistance genes in tobacco and tomato. Plant Cell 18:1067-1083.

Hahlbrock, K., Bednarek, P., Ciolkowski, I., Hamberger, B., Heise, A., Liedgens, H., Logemann, E., Nürnberger, T., Schmelzer, E., Somssich, I. E., and Tan, J. 2003. Non-self recognition, transcriptional reprogramming, and secondary metabolite accumulation during plant/pathogen interactions. Proc. Natl. Acad. Sci. U.S.A. 100:14569-14576.

Heise, A., Lippok, B., Kirsch, C., and Hahlbrock, K. 2002. Two immediate-early pathogen-responsive members of the AtCMPG gene family in Arabidopsis thaliana and the W-box-containing elicitor-response element of AtCMPG1. Proc. Natl. Acad. Sci. U.S.A. 99:9049-9054.

Johnson, C. S., Kolevski, B., and Smyth, D. R. 2002. TRANSPARENT TESTA GLABRA2, a trichome and seed coat development gene of Arabidopsis, encodes a WRKY transcription factor. Plant Cell 14:13591375.

Kim, C. Y., and Zhang, S. 2004. Activation of a mitogen-activated protein kinase cascade induces WRKY family of transcription factors and defense genes in tobacco. Plant J. 38:142-151.

Kirsch, C., Logemann, E., Lippok, B., Schmelzer, E., and Hahlbrock, K. 2001. A highly specific pathogen-responsive promoter element from the immediate-early activated CMPG1 gene in Petroselinum crispum. Plant J. 26:217-227.

Koncz, C., Martini, N., Szabados, L., Hrouda, M., Bachmair, A., and Schell, J. 1994. Specialized vectors for gene tagging and expression studies. Plant Mol. Biol. Man. B2:1-22.

Laloi, C., Mestres-Ortega, D., Marco, Y., Meyer, Y., and Reichheld, J.-P. 2004. The Arabidopsis cytosolic thioredoxin $h 5$ gene induction by oxidative stress and its W-box-mediated response to pathogen elicitor. Plant Physiol. 134:1006-1016.

Landt, O., Grunert, H.-P., and Hahn, U. 1990. A general method for rapid site-directed mutagenesis using the polymerase chain reaction. Gene 96:125-128.

Li, J., Brader, G., and Palva, E. T. 2004. The WRKY70 transcription factor: A node of convergence for jasmonate-mediated and salicylate-mediated signals in plant defense. Plant Cell 16:319-331.

Li, J., Brader, G., Kariola, T., and Tapio Palva, E. 2006. WRKY70 modulates the selection of signaling pathways in plant defense. Plant $\mathrm{J}$. 46:477-491.

Liu, Y., Schiff, M., and Dinesh-Kumar, S. P. 2004. Involvement of MEK1 MAPKK, NTF6 MAPK, WRKY/MYB transcription factors, COI1 and CTR1 in $N$-mediated resistance to tobacco mosaic virus. Plant J. 38:800-809.

Luo, M., Dennis, E. S., Berger, F., Peacock, W. J., and Chaudhury, A. 2005. MINISEED3 (MINI3), a WRKY family gene, and HAIKU2 (IKU2), a leucine-rich repeat (LRR) KINASE gene, are regulators of seed size in Arabidopsis. Proc. Natl. Acad. Sci. U.S.A. 102:1753117536.

Mahalingam, R., Shah, N., Scrymgeour, A., and Fedoroff, N. 2005. Temporal evolution of the Arabidopsis oxidative stress response. Plant Mol. Biol. 57:709-730.

Maleck, K., Levine, A., Eulgem, T., Morgen, A., Schmid, J., Lawton, K., Dangl, J. L., and Dietrich, R. A. 2000. The transcriptome of Arabidopsis thaliana during systemic acquired resistance. Nat. Genet. 26:403410.

Menke, F. L. H., Kang, H.-G., Chen, Z., Park, J. M., Kumar, D., and Klessig, D. F. 2005. Tobacco transcription factor WRKY1 is phosphorylated by the MAP kinase SIPK and mediates HR-like cell death in tobacco. Mol Plant-Microbe Interact. 18:1027-1034.

Narusaka, Y., Narusaka, M., Seki, M., Ishida, J., Shinozaki, K., Nan, Y. O. H., Park, P., Shiraishi, T., and Kobayashi, M. 2005. Cytological and mo- 
lecular analyses of non-host resistance of Arabidopsis thaliana to Alternaria alternata. Mol. Plant Pathol. 6:615-627.

Navarro, L., Zipfel, C., Rowland, O., Keller, I., Robatzek, S., Boller, T., and Jones, J. D. G. 2004. The transcriptional innate immune response to flg22. Interplay and overlap with avr gene-dependent defense responses and bacterial pathogenesis. Plant Physiol. 135:1113-1128.

Noutoshi, Y., Ito, T., Seki, M., Nakashita, H., Yoshida, S., Marco, Y., Shirasu, K., and Shinozaki, K. 2005. A single amino acid insertion in the WRKY domain of the Arabidopsis TIR-NBS-LRR-WRKY-type disease resistance protein SLH1 (sensitive to low humidity 1) causes activation of defense responses and hypersensitive cell death. Plant J. 43:873-888

Nürnberger, T., Nennstiel, D., Jabs, T., Sacks, W., Hahlbrock, K., and Scheel, D. 1994. High affinity binding of a fungal oligopeptide elicitor to parsley plasma membranes triggers multiple defense responses. Cell 78:449-460.

Panstruga, R., Kim, M. C., Cho, M. J., and Schulze-Lefert, P. 2003. Testing the efficiency of dsRNAi constructs in vivo in a transient expression assay tested on two fluorescent proteins. Mol. Biol. Rep. 30:135-140.

Petersen, M., Brodersen, P., Naested, H., Andreasson, E., Lindhart, U., Johansen, B., Nielsen, H. B., Lacy, M., Austin, M. J., Parker, J. E., Sharma, S. B., Klessig, D. F., Martienssen, R., Mattsson, O., Jensen, A. B., and Mundy, J. 2000. Arabidopsis MAP kinase 4 negatively regulates systemic acquired resistance. Cell 103:1111-1120.

Raventós, D., Jensen, A. B., Rask, M.-B., Casacuberta, J. M., Mundy, J., and San Segundo, B. 1995. A 20 by cis-acting element is both necessary and sufficient to mediate elicitor response of a maize PRms gene. Plant J. 7:147-156.

Robatzek, S., and Somssich, I. E. 2002. Targets of AtWRKY6 regulation during plant senescence and pathogen defense. Genes Dev. 16:1139-1149.

Rocher, A., Dumas, B., and Cock, J. M. 2005. A W-box is required for full expression of the SA-responsive gene SFR2. Gene 181-192.

Rushton, P. J., Torres, J. T., Parniske, M., Wernert, P., Hahlbrock, K., and Somssich, I. E. 1996. Interaction of elicitor-induced DNA binding proteins with elicitor response elements in the promoters of parsley PR1 genes. EMBO (Eur. Mol. Biol. Organ.) J. 15:5690-5700.

Rushton, P. J., Reinstädler, A., Lipka, V., Lippok, B., and Somssich, I. E. 2002. Synthetic plant promoters containing defined regulatory elements provide novel insights into pathogen- and wound-induced signaling. Plant Cell 14:749-762.

Sambrook, J., Fritsch, E. F., and Maniatis, T. 1989. Molecular Cloning: A Laboratory Manual, 2nd ed. Cold Spring Harbor Laboratory Press, Cold Spring Harbor, NY, U.S.A.
Staswick, P. E., Tiryaki, I., and Rowe, M. L. 2002. Jasmonate response locus JAR1 and several related Arabidopsis genes encode enzymes of the firefly luciferase superfamily that show activity on jasmonic, salicylic and indole-3-actetic acids in an assay for adenylation. Plant Cell 14:1405-1415.

Trezzini, G. F., Horrichs, A., and Somssich, I. E. 1993. Isolation of putative defense-related genes from Arabidopsis thaliana and expression in fungal elicitor-treated cells. Plant Mol. Biol. 21:385-389.

Turck, F., Zhou, A., and Somssich, I. E. 2004. Stimulus-dependent, promoter-specific binding of transcription factor WRKY1 to its native promoter and the defense-related gene PcPR1-1 in parsley. Plant Cell $16: 2573-2585$.

Ülker, B., and Somssich, I. E. 2004. WRKY transcription factors: From DNA binding towards biological function. Curr. Opin. Plant Biol. 7:491-498.

van de Löcht, U., Meier, I., Hahlbrock, K., and Somssich, I. E. 1990. A $125 \mathrm{bp}$ promoter fragment is sufficient for strong elicitor-mediated gene activation in parsley. EMBO (Eur. Mol. Biol. Organ.) J. 9:2945-2950.

Wan, J., Zhang, S., and Stacey, G. 2004. Activation of a mitogen-activated protein kinase pathway in Arabidopsis by chitin. Mol. Plant Pathol. 5:125-135.

Xu, X., Chen, C., Fan, B., and Chen, Z. 2006. Physical and functional interactions between pathogen-induced Arabidopsis WRKY18, WRKY40, and WRKY60 transcription factors. Plant Cell 18:13101326.

Yamamoto, S., Nakano, T., Suzuki, K., and Shinshi, H. 2004. Elicitor-induced activation of transcription via W box-related cis-acting elements from a basic chitinase gene by WRKY transcription factors in tobacco. Biochim. Biophys. Acta 1679:279-287.

Yoda, H., Ogawa, M., Yamaguchi, Y., Koizumi, N., Kusano, T., and Sano, H. 2002. Identification of early-responsive genes associated with the hypersensitive response to tobacco mosaic virus and characterization of a WRKY-type transcription factor in tobacco plants. Mol. Gen. Genomics 267:154-161

Yu, D., Chen, C., and Chen, Z. 2001. Evidence for an important role of WRKY DNA binding proteins in the regulation of NPR1 gene expression. Plant Cell 13:1527-1539.

Zheng, Z., Qamar, S. A., Chen, Z., and Mengiste, T. 2006. Arabidopsis WRKY33 transcription factor is required for resistance to necrotrophic fungal pathogens. Plant J. 48:592-605.

Zimmerli, L., Stein, M., Lipka, V., Schulze-Lefert, P., and Somerville, S. 2004. Host and non-host pathogens elicit different jasmonate/ethylene responses in Arabidopsis. Plant J. 40:633-646. 